\title{
Science Cartoon
}

\section{Within and beyond my control}

\author{
Beom Sun Chung, Min Suk Chung \\ Department of Anatomy, Ajou University School of Medicine, Suwon, Korea
}

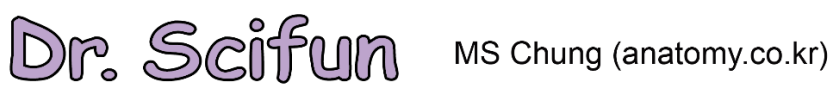

Within and beyond my control

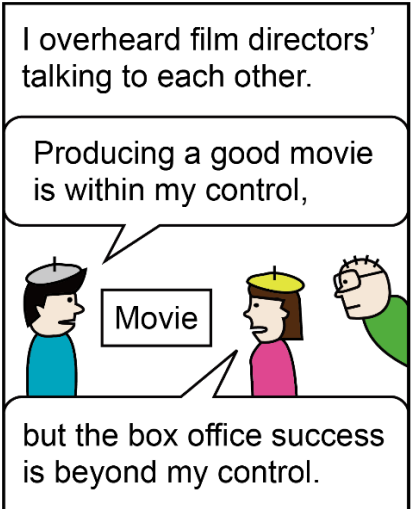

Even if the movie

is well-made,

people may not watch it.

Received: August 28, 2020

Accepted: September 7, 2020

Correspondence to Min Suk Chung dissect@ajou.ac.kr

ORCID

Beom Sun Chung

http://orcid.org/0000-0002-3644-9120

Min Suk Chung

http://orcid.org/0000-0002-0527-9763

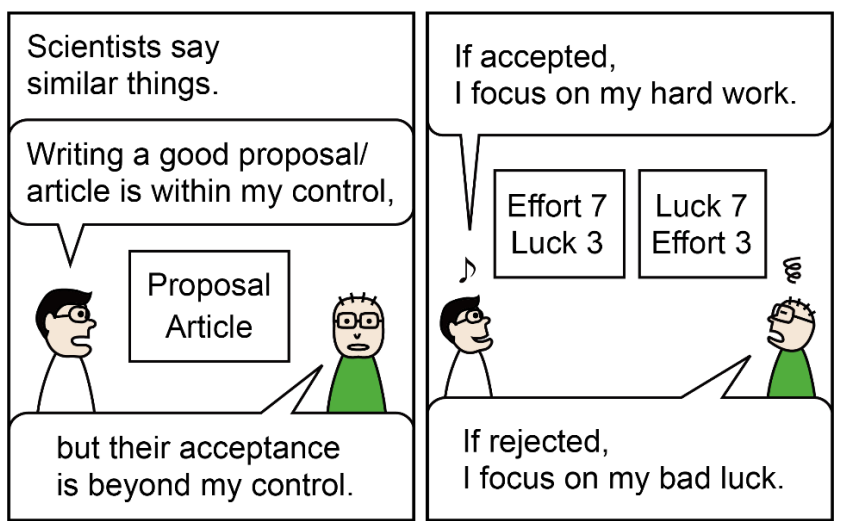

Sometimes, my research grant proposal is accepted even though I did not put a lot of effort into writing it. In such a case, I say it is " $70 \%$ effort and $30 \%$ luck." Other times, my proposal is rejected even though I put a lot of effort into it. Then, I say it is " $70 \%$ luck and $30 \%$ effort." Framing it this way is good for my mental health. 


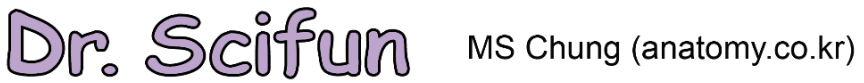

Novel, not a novel
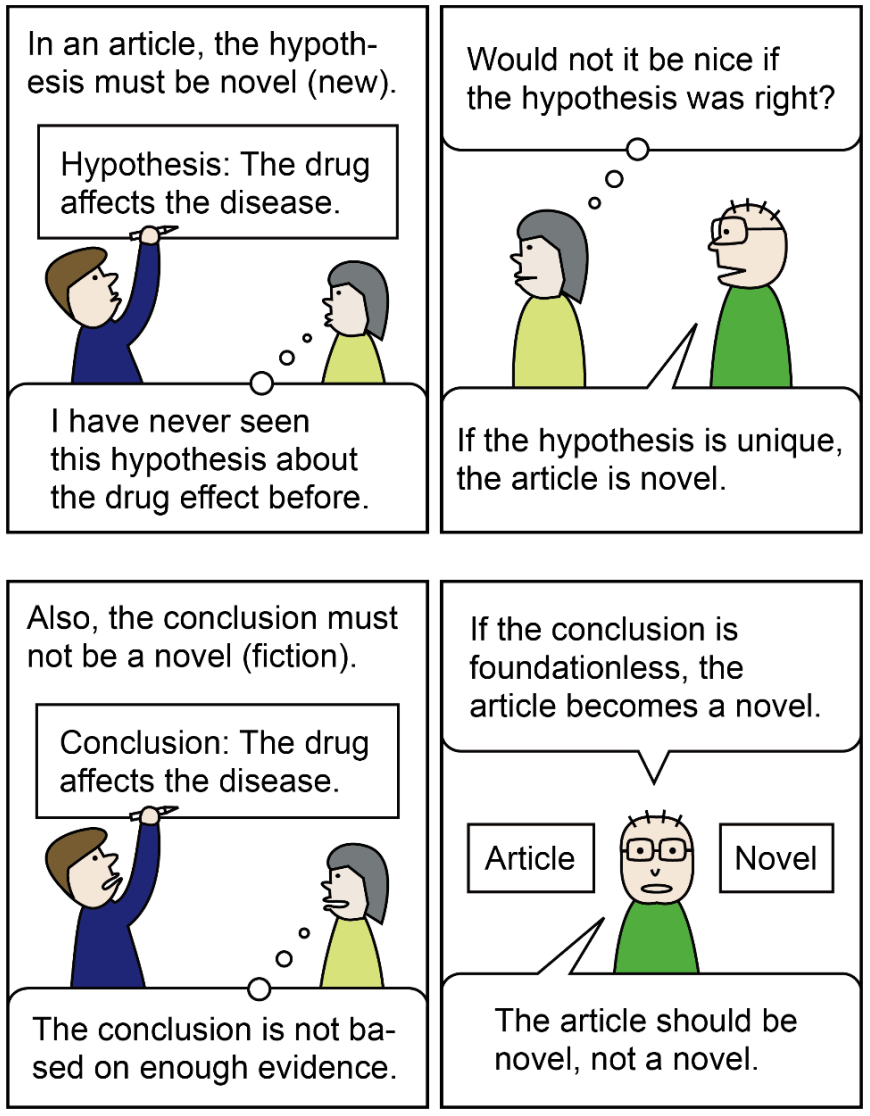

Research is the process of verifying a hypothesis. The process includes the hypothesis, materials and methods, results, and conclusion. The hypothesis and conclusion are two different things. If a scientist is confused and writes the hypothesis as if it is the conclusion, the article turns into a novel (fiction). This is the moment when a scientist changes into a swindler.

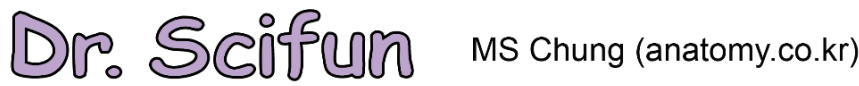

Achievement and ability

$\begin{aligned} & \text { I told a graduate student } \\ & \text { that achievement and } \\ & \text { ability are different. }\end{aligned}$
$\begin{aligned} & \text { For example, } \\ & \text { icles, you'll get the degree } \\ & \text { earlier, and be widely } \\ & \text { recognized as a scientist. } \\ & \text { while ability is the skills } \\ & \text { to write the articles. }\end{aligned}$

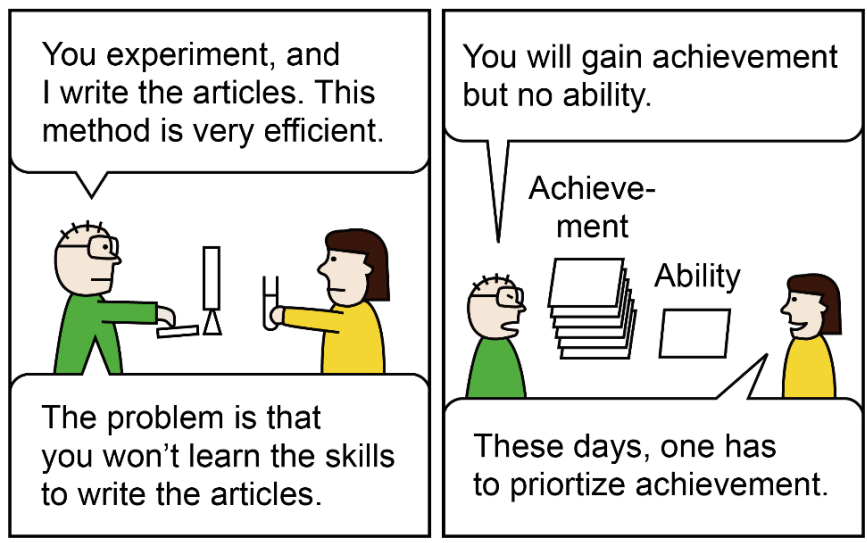

When I was a graduate student, it took me a lot of time to improve my article writing skills. It even took me half a year to finish writing my first article, during which time I was scolded by my academic advisor. However, after that harsh time, I have been able to write as many articles as I need. In the long term, ability is more important than achievement. 


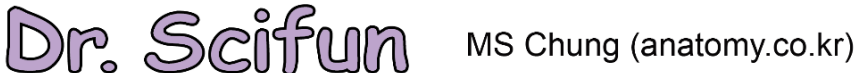

Power of grant and article

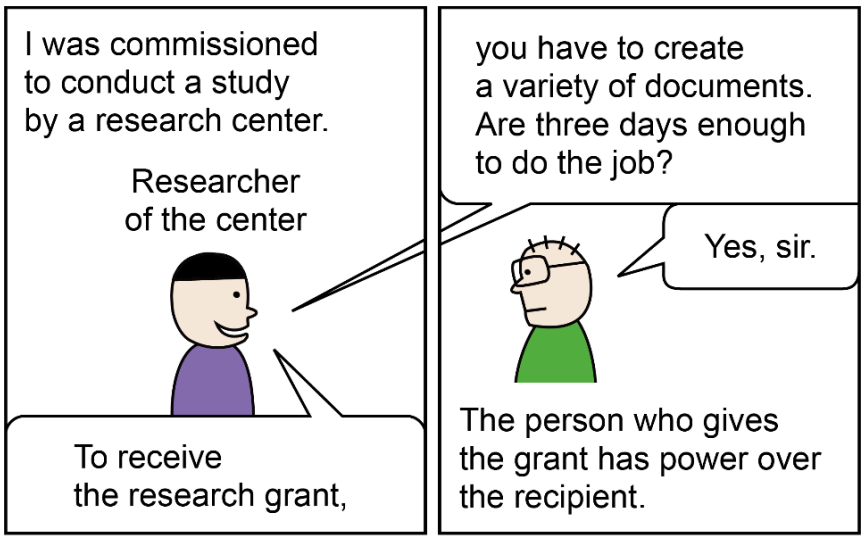

I wrote an article on the commissioned study. I decided to make the other researcher a co-author.

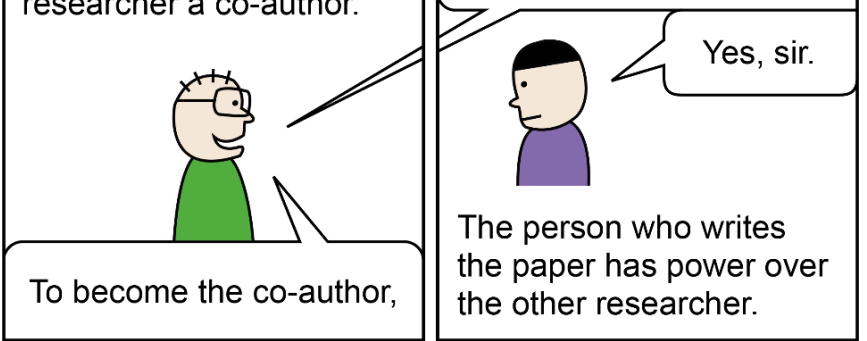

Researchers at academic institutions and research centers can form a team to carry out an investigation based on a research grant and write an article. However, they cannot give authorship to each other only because of the research grant. Like in the comic strip, they need to ask for a fair exchange of work.

\section{Conflict of Interest}

No potential conflict of interest relevant to this article was reported.

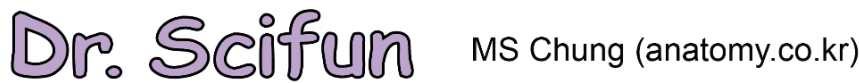

After drawing hundreds of comics

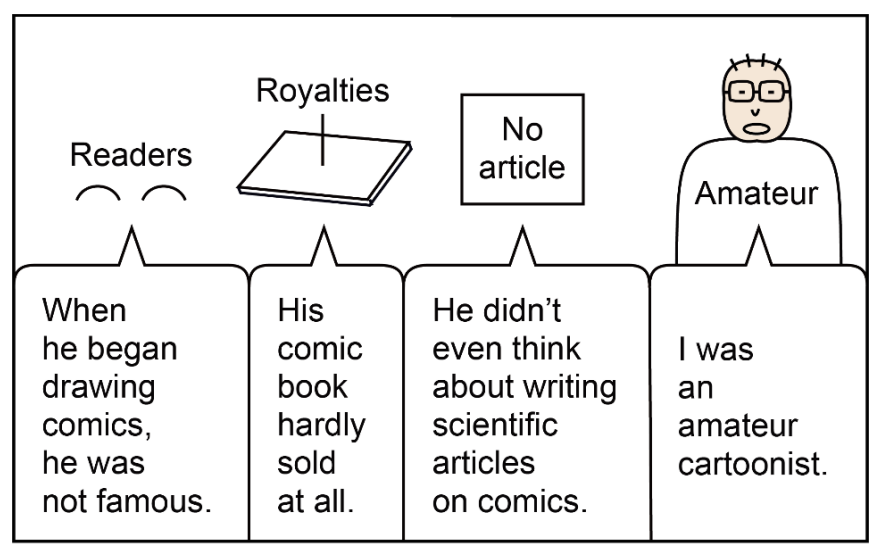

\begin{tabular}{|l|l|l|l|}
\hline $\begin{array}{l}\text { After drawing } \\
\text { hundreds of } \\
\text { comics, } \\
\text { he got famous } \\
\text { through social } \\
\text { network service. }\end{array}$ & $\begin{array}{l}\text { His } \\
\text { comic } \\
\text { book } \\
\text { sells } \\
\text { well. }\end{array}$ & $\begin{array}{l}\text { He has } \\
\text { written } \\
\text { scientific } \\
\text { articles } \\
\text { on } \\
\text { comics. }\end{array}$ & $\begin{array}{l}\text { I look like } \\
\text { a }\end{array}$ \\
professional \\
cartoonist.
\end{tabular}

When I first drew comics, many people called me "pathetic." Some people scolded me for drawing comics, saying, "Do you, as a professor, have nothing to do but write comics?" But I kept creating comics with the belief that someone would acknowledge me someday. Nowadays, I am making a bit of money and winning a little fame with comics; people are becoming envious of me.

\section{Funding}

This work was supported by the National Research Foundation of Korea (NRF) grant funded by the Korea government (MSIT) (No. 2019R1F1A1059842). 